TP Periodica Polytechnica Chemical Engineering

61(2), pp. 93-101, 2017

https://doi.org/10.3311/PPch.9269

Creative Commons Attribution (i)

RESEARCH ARTICLE

\section{Determination of Phenolic Hydroxyl Groups in Technical Lignins by Ionization Difference Ultraviolet Spectrophotometry ( $\Delta \varepsilon$-IDUS method)}

Werner Marcelo Goldmann ${ }^{1 *}$, Juha Ahola ${ }^{1}$, Otto Mankinen ${ }^{2}$, Anu M. Kantola $^{2}$, Sanna Komulainen ${ }^{2}$, Ville-Veikko Telkki ${ }^{2}$, Juha Tanskanen ${ }^{1}$

Received 04 April 2016; accepted after revision 12 June 2016

\begin{abstract}
The amount of hydroxyl groups, particularly phenolic, is one of the most important parameters in lignins, as it is an indicator of lignin reactivity. Ultraviolet (UV) Spectrophotometry is a simple and inexpensive method for determining phenolic hydroxyls in lignin. Ionization Difference Ultraviolet Spectrophotometry ( $\Delta \varepsilon$-method) relies on the analysis of solubilized lignin at neutral and alkaline conditions with a UV spectrophotometer. We added a slope analysis to the $\Delta \varepsilon$-method and dubbed the resulting method $\Delta \varepsilon-I D U S$ (Ionization Difference UV Spectrophotometry). We assessed the reliability of $\Delta \varepsilon-I D U S$ by studying the well-known Indulin AT lignin. Additionally, $\Delta \varepsilon$-IDUS was applied to a previously uncharacterized milox lignin. When compared to ${ }^{13} C$-NMR, $\Delta \varepsilon$-IDUS underestimated the amount of phenolic hydroxyls for Indulin AT, possibly due to neglecting second phenolic hydroxyls in some lignin units, which resist ionization because of steric hindrance. Nevertheless, the results agreed with previously reported values and confirm that $\Delta \varepsilon-I D U S$ is useful to screen lignins based on their phenolic hydroxyl group content.
\end{abstract}

\section{Keywords}

IDUS, ${ }^{13} C$-NMR, lignin, NMR, phenolic hydroxyl, $\Delta \varepsilon$
${ }^{1}$ Chemical Process Engineering, Faculty of Technology, University of Oulu,
P.O. Box 4300, FIN-90014 University of Oulu, Finland,

${ }^{2}$ NMR Research Group, Faculty of Science, University of Oulu,

P.O. Box 4300, FIN-90014 University of Oulu, Finland

*Corresponding author, e-mail: werner.goldmann@oulu.fi

\section{Introduction}

Despite being one of the most abundant biomaterials available, lignin has its potential mostly untapped, as to this day there are no widespread applications. It can be used as a low-grade fuel for the recovery boiler in the pulp and paper industry; however, its potential lies in its phenolic structure. Lignin is generally defined as a complex, highly cross-linked, co-polymer of three phenyl-propanoid units, namely p-coumaryl, coniferyl, and sinapyl alcohols, called monolignols [1]. The $R$ substituents in positions 3 and 5 depend on the alcohol of origin. They can be hydrogens in both positions ( $\mathrm{p}$-coumaryl), one methoxy group and one hydrogen (coniferyl), or two methoxy groups (sinapyl) (Fig. 1a). Lignin aromatic carbons can be numbered according to the position relative to the propanoid chain, where the chain carbons can be denoted with Greek letters to specify the primary $(\alpha)$, secondary $(\beta)$, and tertiary $(\gamma)$ carbons in the chain. The aromatic portions or units (without the propanoid side-chain) are named $\mathrm{p}$-hydroxyphenyl $(\mathrm{H}$, additative of p-coumaryl), guaiacyl ( $G$, additative of coniferyl), and syringyl (S, additative of sinapyl) and they form the aromatic backbone of lignin fragments (Fig. 1b). Thus, lignins that contain a large proportion of one of these aromatic units can be named accordingly, such as guaiacyl lignins from softwood [3].

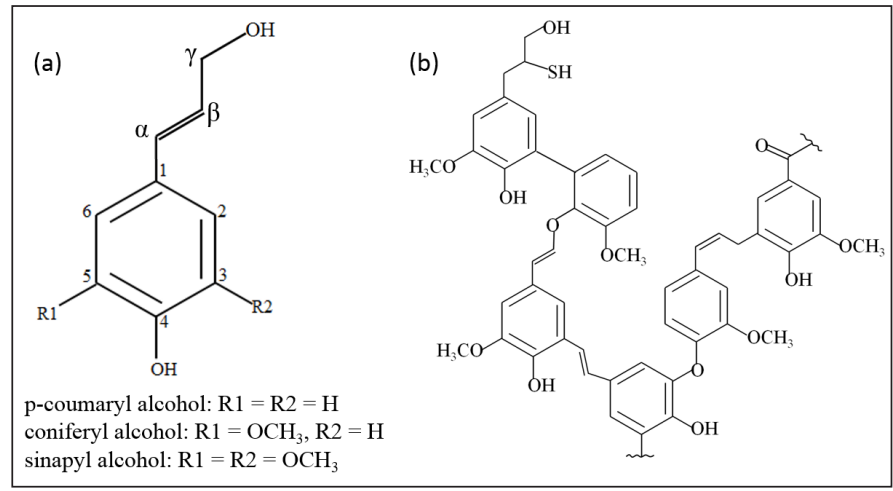

Fig. 1 (a) Structure units of lignin, (b) lignin model fragment, adapted from [2]

Given that isolated technical lignin can be obtained from different sources (softwood, hardwood, non-wood like wheat straw) and by different methods (kraft, soda-AQ, sulfite, 
organosolv, steam explosion) [3, 4], each of these technical lignins has properties particular to it. Regarding the chemical structure of lignin, one of the most important characteristics is the hydroxyl (-OH) group content. It is an indicator of the lignin reactivity [5] and by determining the hydroxyl content of different lignin samples, it is possible to compare them in terms of their relative $-\mathrm{OH}$ group content and reactivity. The hydroxyl groups give lignin its potential to be utilized in a variety of technical applications, such as thermosets [6], rubbers [7], polymer blends [8] and composites (including thermoplastic composites) [9], polyurethane foams [10], and dispersants [11].

Lignin hydroxyl groups can be aliphatic (primary, secondary) or aromatic (phenolic). They can be found in condensed and uncondensed units. Condensed units are not normally end-groups of the lignin molecule and are typically bound in positions 2, 3, 5, or 6 . Uncondensed units lack these linkages and can be end units [12]. Common linkages include but are not limited to $\beta-5,5-5,4-\mathrm{O}-5$, and the most common $\beta-\mathrm{O}-4$ [3]. Methoxy $\left(-\mathrm{OCH}_{3}\right)$ substitution in positions 3 or 5 does not make the unit condensed, but rather, as previously mentioned, gives it the unit name guaiacyl or syringyl [13]. Additionally, condensed and uncondensed units can have a carbonyl group in $\alpha$-position or a double bond in $\alpha-\beta$ position, in which case they can also be referred to as conjugated units [14]. Therefore, a phenolic hydroxyl group typically receives the name derived from its unit e.g. conjugated condensed phenolic hydroxyl group (Fig. 2).

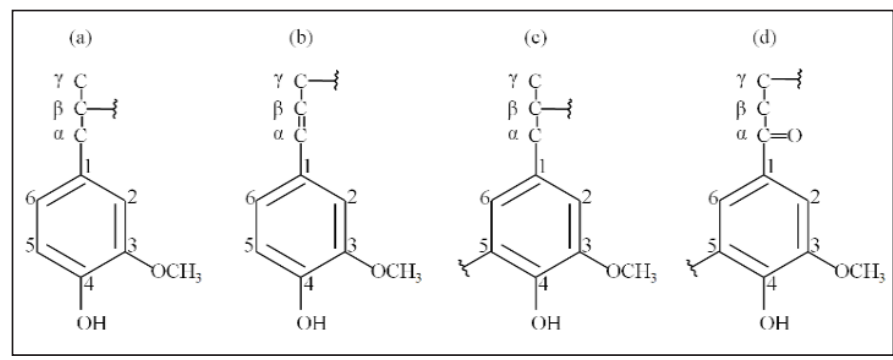

Fig. 2 Condensation and conjugation (a) Unconjugated-uncondensed, (b) conjugated-uncondensed, (c) unconjugated-condensed,

(d) conjugated-condensed

Some properties of lignins can be determined from the solid bulk, such as density, moisture, and solubility in various solvents. Other properties require more elaborate methodologies, such as Gel-Permeation Chromatography (GPC) for molecular weight and polydispersity $[15,16,17]$. Additionally, Pyrolysis Gas Chromatography Mass Spectrometry (Py-GC/MS) has been utilized for characterization of degradation products [18] and Thermogravimetric Analysis coupled with MS (TG/MS) to estimate the amount of functional groups (as well as origin and isolation method) in lignin [19].

Fourier-Transform Infrared (FTIR) Spectroscopy is a method which has been used for characterization of functional groups in lignin, with the disadvantage that the post-processing of the data has proven to be relatively laborious due to the complexity of the spectrograms. Therefore, the method has been used mostly as a complement to other methods [20].

Nuclear Magnetic Resonance (NMR) spectroscopy in analysis of lignin is commonly used due to its precision and ability to identify the types of hydroxyl groups in the sample (e.g. phenolic, aliphatic or carboxylic). With NMR it is possible to elucidate the amount of both aliphatic and phenolic hydroxyl groups, and with ${ }^{31} \mathrm{P}-\mathrm{NMR}$ in particular, also their structural origin (aliphatic, G, S, H, catechol, condensed, uncondensed). However, the methods normally require laborious preparation and derivatization of the lignin samples $[13,20,21]$. There have been successful attempts to analyze lignin without derivatization, using DMSO- $\mathrm{d}_{6}$ under specific conditions of complete dryness (no water) with no base and no acid present except for the lignin carboxylic acid groups [22]. Additionally, NMR has proven to exhibit interlaboratory variations in analyses results [23].

A relatively simple determination of the phenolic hydroxyl groups $\left(\mathrm{OH}_{\mathrm{ph}}\right)$ in lignin can be done by Ultraviolet Spectrophotometry. The method is known as Ultraviolet Ionization Difference Spectrophotometry, UV-Difference Spectrophotometry, $\Delta \varepsilon$-method, or as it is used in this work: $\Delta \varepsilon$-IDUS. The analysis principle is based on the so-called bathochromic and hyperchromic shifts in the absorption spectrum of lignin based on ionization of the hydroxyl groups at alkaline conditions [24, 25]. The bathochromic shift occurs when the absorption maximum is displaced to a longer wavelength, while a hyperchromic shift entails an increase in absorption intensity at a certain wavelength [26]. By subtracting the neutral spectrum from the alkaline spectrum, a so-called ionization difference spectrum ( $\Delta$-spectrum) is obtained, with characteristic maxima based on the type of phenolic hydroxyl groups. The method assumes complete dissolution of the lignin in the solvent. If this condition is not met, the actual amount of phenolic hydroxyl groups will be underestimated. Through calibration with model compounds, it is possible to apply the method to lignins of different origins, provided that they are soluble at neutral and alkaline conditions in the solvent of choice [24].

In this work we modified the sample analysis procedure for the $\Delta \varepsilon$-method [14, 25], using slope analysis, and dubbed the resulting method $\Delta \varepsilon$-IDUS (Ionization Difference Ultraviolet Spectrophotometry). We assessed the reliability of the $\Delta \varepsilon$-IDUS method by studying a well-known Indulin AT lignin. The results were compared with the literature values. Furthermore, we applied the $\Delta \varepsilon$-IDUS method to a previously uncharacterized milox lignin. ${ }^{13} \mathrm{C}$-NMR analysis of both lignins was also performed to obtain reference values and additional information about the $\mathrm{OH}$ groups not observable with the $\Delta \varepsilon$-IDUS method. This allowed us to obtain information on the difference in results between methods, and the relative amount of phenolic hydroxyl groups between the two different technical lignins. 


\section{Materials and methods}

\subsection{Technical lignins}

Indulin AT kraft pine lignin from MeadWestvaco (Richmond, VA, USA) and a milox organosolv birch lignin were analyzed. The milox process is a multi-stage pulping process with peroxyformic acid and formic acid treatment stages [27, 28]. Table 1 shows the variability of results in determining the phenolic hydroxyl content in Indulin AT lignin by different methods and the same method by different authors. The total amount of phenolic hydroxyl groups in Indulin AT is $3.31 \pm 0.50 \mathrm{mmol} / \mathrm{g}$ with 99\% confidence ( $\mathrm{t}$-based confidence interval C.I.). The limited data about the two distinct types of phenolic $\mathrm{OH}$ (condensed and uncondensed) suggests that the uncondensed hydroxyl groups are more prominent than the condensed ones.

Table 1 Phenolic hydroxyl content $\left(\mathrm{mmol}_{\mathrm{OH} / \mathrm{gLignin}}\right)$ of Indulin AT lignin measured by several methods reported in the literature.

\begin{tabular}{lll}
\hline Method & Total $\mathrm{OH}_{\mathrm{ph}}$ & Source \\
\hline${ }^{13} \mathrm{C}-\mathrm{NMR}$ & 3.9 & {$[30]$} \\
${ }^{13} \mathrm{C}-\mathrm{NMR}$ & 3.83 & {$[30]$} \\
${ }^{1} \mathrm{H}-\mathrm{NMR}$ & 2.65 & {$[31]$} \\
${ }^{1} \mathrm{H}-\mathrm{NMR}$ & 3.59 & {$[32]$} \\
${ }^{1} \mathrm{H}-\mathrm{NMR}$ & 3.46 & {$[33]$} \\
${ }^{1} \mathrm{H}-\mathrm{NMR}$ & 3.2 & {$[30]$} \\
${ }^{31} \mathrm{P}-\mathrm{NMR}{ }^{a}$ & 3.63 & {$[13]$} \\
${ }^{31} \mathrm{P}-\mathrm{NMR}{ }^{b}$ & 2.31 & {$[20]$} \\
${ }^{31} \mathrm{P}-\mathrm{NMR}{ }^{c}$ & 3.20 & {$[21]$} \\
${ }^{31} \mathrm{P}-\mathrm{NMR}$ & 2.90 & {$[31]$} \\
${ }^{31} \mathrm{P}-\mathrm{NMR}{ }^{d}$ & 4.11 & {$[30]$} \\
Aminolysis & 3.40 & {$[34]$} \\
Aminolysis & 3.05 & {$[14]$} \\
Chemical & 3.75 & {$[32]$} \\
FTIR/PLS & 3.75 & {$[32]$} \\
Methylation & 3.77 & {$[31]$} \\
UV & 2.49 & {$[33]$} \\
UV & 2.64 & {$[14]$} \\
\hline
\end{tabular}

Uncondensed OHph (mmolOH/gLignin) $a \mathbf{1 . 9 5}, b \mathbf{2 . 3 1}, c$ 1.92,$d \mathbf{2 . 5 5}$

Condensed OHph (mmolOH/gLignin) $a$ 1.67, $b$ 1.28, $c$ n.a., $d$ 1.58

\subsection{Ionization Difference Ultraviolet Spectrophotometry \\ 2.2.1 Sample preparation}

Aqueous buffers of $\mathrm{pH} 12$ and $\mathrm{pH} 6$, as well as a solution of $0.2 \mathrm{M} \mathrm{NaOH}$ were prepared according to [25]. Solutions of Indulin AT and milox lignin were prepared at a concentration of $10 \mathrm{~g} / \mathrm{L}$ with ethylene glycol as solvent. Six samples were prepared by diluting the mother solutions with ultrapure water to concentrations between 0.1 and $5 \mathrm{~g} / \mathrm{L}$. For each analysis, a volume of $50 \mu \mathrm{L}$ from each sample was diluted with $4.95 \mathrm{~mL}$ of each corresponding buffer solution for final concentrations between 0.001 and $0.05 \mathrm{~g} / \mathrm{L} .3 \mathrm{~mL}$ of each solution were introduced in the analysis cuvette and analyzed in a Shimadzu 1800-Series Double Beam UV-Spectrophotometer between the wavelengths of 400 and $230 \mathrm{~nm}$. The quartz cuvette utilized for the UV-Spectrophotometer had a path (width) of $1 \mathrm{~cm}$ and maximum capacity of $4.3 \mathrm{~mL}$.

The neutral (pH 6) spectrum of each sample was subtracted from its alkaline spectrum to yield a spectrum, from which the difference absorbance maxima at about $300 \mathrm{~nm}$ and $360 \mathrm{~nm}$ were recorded.

\subsubsection{Slope analysis}

The slope analysis is based on the $\Delta \varepsilon$-method, with modification on how the values from the UV-spectra are obtained. We found experimentally that the mass extinction coefficient measurement was unstable with respect to concentration. By using slope analysis, the mass extinction coefficient can be calculated from the slope of a line fitted to data of absorbance and concentration and the instability of the measurement reduced.

According to the Beer-Lambert equation [35] , the absorbance maximum at a given wavelength for the lignin samples is

$$
A_{\max }=a_{\max } b c
$$

where $A_{\max }$ is the dimensionless absorbance, $a_{\max }$ is the mass absorptivity or extinction coefficient in $\mathrm{L} \cdot \mathrm{g}^{-1} \cdot \mathrm{cm}^{1}, b$ is the path length in $\mathrm{cm}$, and $c$ is the concentration of lignin in $\mathrm{g} / \mathrm{L}$. Consequently, within concentration ranges where the BeerLambert Law applies, the absorbance increases linearly with increasing concentration with slope $a_{\max } b$ for a given wavelength. For each of the alkaline spectra, the neutral spectrum 1 is subtracted from the alkaline spectrum 2.

$$
\Delta A_{\max }=A_{\max 2}-A_{\max 1}=a_{\max 2} b_{2} c_{2}-a_{\max 1} b_{1} c_{1}
$$

If identically dimensioned cuvettes are utilized, and given that both spectra come from the same original sample, the terms $b$ and $c$ are constant, and Eq. (2) simplifies to

$$
\Delta A_{\max }=\left(a_{\max 2}-a_{\max 1}\right) b c=\Delta a_{\max } b c
$$

In order to minimize error in the determination, the $\Delta A$ maxima $\left(\Delta A_{\max }\right)$ are measured as a function of concentration. The two characteristic maxima of lignin will normally fall around the wavelengths of 300 (295-305 for Indulin AT) and 360 (365-375 for Indulin AT) $\mathrm{nm}$. Linear equations correlating the difference absorbance maxima with the sample lignin concentration are fitted to the data, each with their particular slope $\Delta a_{\max }$ (maximum difference mass absorptivity). The conversion of $\Delta a_{\max }$ values to the corresponding amount of phenolic hydroxyl groups (typically reported in $\mathrm{mmol}_{\mathrm{OH}} / \mathrm{g}_{\mathrm{Lignin}}$ or $\mathrm{wt} \%$ ) is based on the molar difference absorptivity maxima $\left(\Delta \varepsilon_{\max }\right)$ in $\mathrm{L} \cdot \mathrm{mol}^{-1} \cdot \mathrm{cm}^{-1}$ of model structures. The molar difference absorptivity or 
Table 2 Calculation of $\mathrm{OH}_{\mathrm{ph}}$ in $\mathrm{mmol} / \mathrm{g}$ given difference absorptivity maxima $\Delta \boldsymbol{a}_{\boldsymbol{k}}^{\lambda} \mathrm{L} \cdot \mathrm{mol}^{-1} \cdot \mathrm{g}^{-1}$, where $\mathrm{k}$ is the ionization level, and $\lambda$ the wavelength in $\mathrm{nm}$. The 'max' subscript has been omitted for visual clarity

\begin{tabular}{llllll}
\hline Calculation & C5-substituted (Condensed) & Uncondensed & Conjugated & Unconjugated & Total \\
\hline Lin \& Dence & & $0.223 \Delta a_{1}^{300}+0.078 \Delta a_{1}^{315}$ & & $0.078 \Delta a_{1}^{315}+0.043 \Delta a_{1}^{350}$ & $0.223 \Delta a_{1}^{300}+0.078 \Delta a_{1}^{315}$ \\
[24] & $0.112 \Delta a_{1}^{320}$ & $+0.043 \Delta a_{1}^{350}+0.032 \Delta a_{1}^{370}$ & $+0.032 \Delta a_{1}^{370}+0.056 \Delta a_{1}^{380}$ & $0.223 \Delta a_{1}^{300}+0.112 \Delta a_{1}^{320}$ & $+0.043 \Delta a_{1}^{350}+0.032 \Delta a_{1}^{370}$ \\
& & $+0.056 \Delta a_{1}^{380}$ & & $+0.056 \Delta a_{1}^{380}+0.112 \Delta a_{1}^{320}$ \\
\hline & & & & $0.250 \Delta a_{2}^{300}+0.059 \Delta a_{2}^{360}$ & $0.250 \Delta a_{2}^{300}+0.107 \Delta a_{2}^{360}$ \\
Gärtner [14] & $0.250\left(\Delta a_{2}^{300}-\Delta a_{1}^{300}\right)$ & $0.250 \Delta a_{1}^{300}+0.107 \Delta a_{1}^{360}$ & $0.048 \Delta a_{2}^{360}$ & \\
\& Zakis [25] & $+0.107\left(\Delta a_{2}^{300}-\Delta a_{1}^{300}\right)$ & & & & \\
\hline
\end{tabular}

extinction of model structures or compounds is commonly represented by $\Delta \varepsilon$ (after which the $\Delta \varepsilon$-method is named). The numerical procedure is dependent on the model structures and levels of ionization and has been reported elsewhere [14, 24, 25]. A brief comparison of the formulae is presented in Table 2.

Zakis [25] and Gärtner et al. [14] utilize two ionization levels, the first solution being alkaline at $\mathrm{pH} 12$ and the second super-alkaline at $0.2 \mathrm{M} \mathrm{NaOH}$. Their approaches differ only conceptually with respect to the model structures. Zakis [25] describes four structure types of phenolic units based on conjugation ( $\alpha$-carbonyl) and C5-substitution (which resist ionization at pH 12) [25]. Gärtner [14] utilizes the same model structures of Zakis [25] (i.e. doesn't recalibrate the method) and reinterprets the conjugated structures to include the structures with an $\alpha-\beta$ double bond. Gärtner [14] also adds a term to the calculation equations which had been missing from the method by Zakis [25], likely due to a misprint. Thus, the total amount of $\mathrm{OH}_{\mathrm{ph}}$ is the same in both methods $[14,25]$.

Lin \& Dence [24] use only the lower ionization level (pH 12) and describes six possible model structures, of which two types cannot be predicted accurately due to ionization resistance caused by steric hindrance. C5-substituted (or so-called weakly acidic [14]) structures have been assumed in this paper to be condensed, although this will not always be necessarily the case.

\section{$2 .{ }^{13} \mathrm{C}-\mathrm{NMR}$ analysis}

\subsubsection{Lignin acetylation}

Prior to the ${ }^{13} \mathrm{C}$ NMR analysis, the lignins were acetylated to provide an improved spectral resolution to the lignin spectra as the acetylation shifts the signals of hydroxyl groups to the carboxyl region in the ${ }^{13} \mathrm{C}$ spectrum [36] as well as to improve solubility and minimize association effects between molecules [37]. The acetylation was conducted using a modified version of the procedure by [38]. Indulin AT kraft lignin (ca. 2 g) was placed into a flask. Freshly prepared acetylation solution (20 mL of 50/50 (v/v) Acetic Anhydride/Pyridine) was added. The flask was plugged with a rubber top. The sample was acetylated for 3 days in complete darkness (i.e. covered) at room temperature under constant stirring. The temperature of the mixture was raised to $50{ }^{\circ} \mathrm{C}$ and the reaction was allowed to continue for 4 more days at this temperature, for a total of 7 days. At the end, no solids were observed in the mixture, which was pitch black. The sample was precipitated using an acidic ( $\mathrm{pH}$ 2) solution composed of $240 \mathrm{~mL}$ of ultrapure water and $200 \mu \mathrm{L}$ of $37 \% \mathrm{HCl}$. The solution was cooled down to near freezing temperature, by placing the beaker in a crushed-ice bath (some $\mathrm{NaCl}$ was added to the ice to decrease the melting point). The acetylated lignin solution was added drop-wise into the precipitation solution under constant stirring. The solution was then filtered through a $1.2 \mu \mathrm{m}$ fiberglass filter in a Büchner funnel. The precipitate was dried at room temperature for 24 hours under a fume hood and subsequently freeze-dried under vacuum overnight. The freeze-dried lignin was accurately weighed out into a $2 \mathrm{~mL}$ vial ( $\sim 150-160 \mathrm{mg})$. A standard solution of trioxane in DMSO was prepared by carefully weighing out the trioxane $(128.8 \mathrm{mg}$ ) and adding $4.0 \mathrm{~mL}$ of DMSO to the solution. From the prepared standard solution, $800 \mu \mathrm{L}$ were added to the lignin vial yielding ca. $200 \mathrm{mg} / \mathrm{mL}$ of lignin solution. The prepared solution was dark brown in color, and no insoluble solids were detected.

\subsubsection{Determination conditions}

${ }^{13} \mathrm{C}-\mathrm{NMR}$ determinations were carried out on $14.1 \mathrm{~T}$ Bruker Avance III 600 spectrometer equipped with a $5 \mathrm{~mm}$ broad-band (BB) probe operating at $150.903 \mathrm{MHz}$ for carbon. Experiments were conducted at room temperature in DMSO-d6 solvent. The positions of the peaks were referenced to the residual solvent peak (DMSO-d6 at $39.5 \mathrm{ppm}$ ). Quantitative ${ }^{13} \mathrm{C}$ spectra were recorded using inversed gate proton decoupling sequence (Bruker standard sequence "zgig30"). The number of scans was 9000, relaxation delay was $36 \mathrm{~s}$ (at least five times $\mathrm{T}_{1}$ ) and the excitation pulse angle was $30^{\circ}$.

\section{Results and discussion \\ $3.1{ }^{13} \mathrm{C}-\mathrm{NMR}$ results}

Quantitative ${ }^{13} \mathrm{C}$ spectra of the acetylated Indulin AT and milox lignin are shown in Fig. 3. A sharp signal for the internal reference (trioxane) is visible at $94 \mathrm{ppm}$. Integrated value of this signal was used for quantitative analysis. 


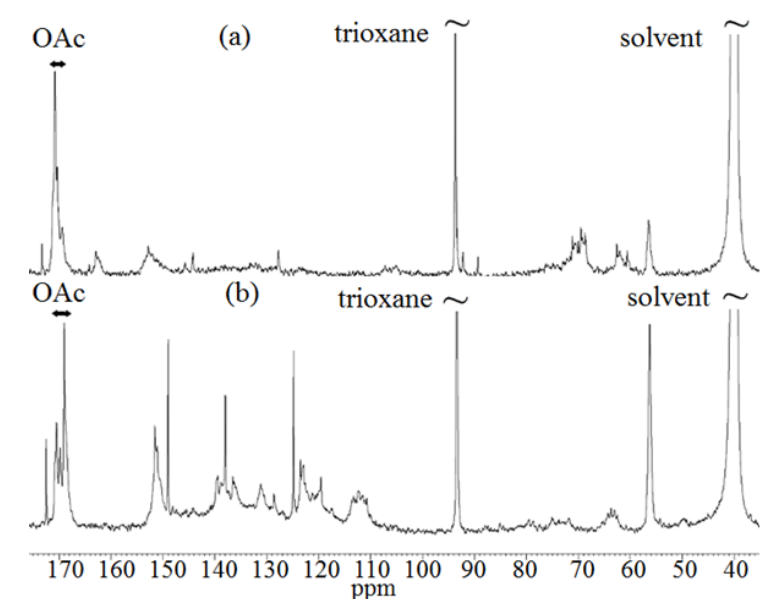

Fig. 3 Quantitative ${ }^{13} \mathrm{C}$ spectrum of (a) milox and (b) Indulin AT lignin

Three clearly resolved signals between 168-171 ppm were observed (Fig. 4), corresponding to acetylated hydroxyl groups $(\mathrm{OAc})$. The signals can be assigned to phenolic OAc (S3, 168$169 \mathrm{ppm})$, secondary OAc (S2, 169-170 ppm) and primary OAc (S1, 170-171 ppm) groups [29]. The signals were used for the determination of hydroxyl content in the acetylated samples. The deconvolution of the spectra in the acetylated hydroxyl group region required altogether six peaks.

For the Indulin AT lignin, phenolic OAc comprises the peaks numbers 4,5 and 6 , secondary OAc the peak number 3 , and primary OAc the peaks numbers 1 and 2 . Assigned peaks corresponds well with previously reported regions [30]. For milox lignin, phenolic OAc comprises the peak number 6, secondary OAc the peaks number 5 and 4 , and primary OAc the peaks number 1,2 and 3. Calculated contents of each hydroxyl type are presented in Table 3. The calculated phenolic hydroxyl content for Indulin AT $(3.84 \mathrm{mmol} / \mathrm{g})$ is in good agreement with the values (2.31-4.11 $\mathrm{mmol} / \mathrm{g}$ ) from previous studies (see Table 1 and [30]).
Table 3 Hydroxyl content of two acetylated lignins in $\mathrm{mmol}_{\mathrm{OH}} / \mathrm{g}_{\mathrm{Lignin}}$ determined by ${ }^{13} \mathrm{C}-\mathrm{NMR}$.

\begin{tabular}{lllll}
\hline Lignin & Primary $(\alpha)$ & Secondary $(\beta)$ & Phenolic $\left(\mathrm{OH}_{\mathrm{ph}}\right)$ & Total $\mathrm{OH}$ \\
\hline Indulin AT & 1.66 & 0.98 & 3.84 & 6.48 \\
Milox & 4.27 & 0.64 & 0.56 & 5.46 \\
\hline
\end{tabular}

There has been ${ }^{31} \mathrm{P}-\mathrm{NMR}$ analyses performed for a milox birch lignin isolated by [39], resulting in 1.31, 1.98, and $1.22 \mathrm{mmol} / \mathrm{g}$ of $\mathrm{OH}_{\mathrm{ph}}$ at the different milox delignification pulping stages, for a total of $4.07,3.57$, and $3.25 \mathrm{mmol} / \mathrm{g}$ of $\mathrm{OH}$. The milox lignin in our study is a result of the combination of the lignin obtained from all stages of delignification, with about one-half to one-third of the amount of $\mathrm{OH}_{\mathrm{ph}}$ and 50 to $70 \%$ higher amount of total $\mathrm{OH}$ than the milox lignins analyzed by ${ }^{31}$ P-NMR by [39]. On the other hand, the milled wood lignin (MWL) analyzed by [39] bears particular similarities in hydroxyl content as it was determined on milox lignin in this paper. The MWL had 4.22 of $\mathrm{OH}_{\text {aliphatic }}$ and $1.01 \mathrm{of} \mathrm{OH}_{\mathrm{ph}}$ for a total of $5.32 \mathrm{mmol}_{\mathrm{OH}} / \mathrm{g}$. Lignin properties seem to be sensitive to specifics in delignification operation conditions despite similar basic process, and cooking chemicals. Additionally, our study suggests that it is possible to isolate birch lignin by milox-type peroxyformic and formic acid-based process without the final lignin product suffering significant structural changes with respect to the total $\mathrm{OH}$ content.

Even though Indulin AT and milox lignin appear to have about the same amount of total $\mathrm{OH}$ (6.48 and 5.46 respectively), according to the ${ }^{13} \mathrm{C}-\mathrm{NMR}$ analysis, Indulin AT has predominantly phenolic hydroxyl groups $(3.84 \mathrm{mmol} / \mathrm{g})$ whereas milox lignin has a dominant amount of aliphatic hydroxyl groups $(4.91 \mathrm{mmol} / \mathrm{g})$.
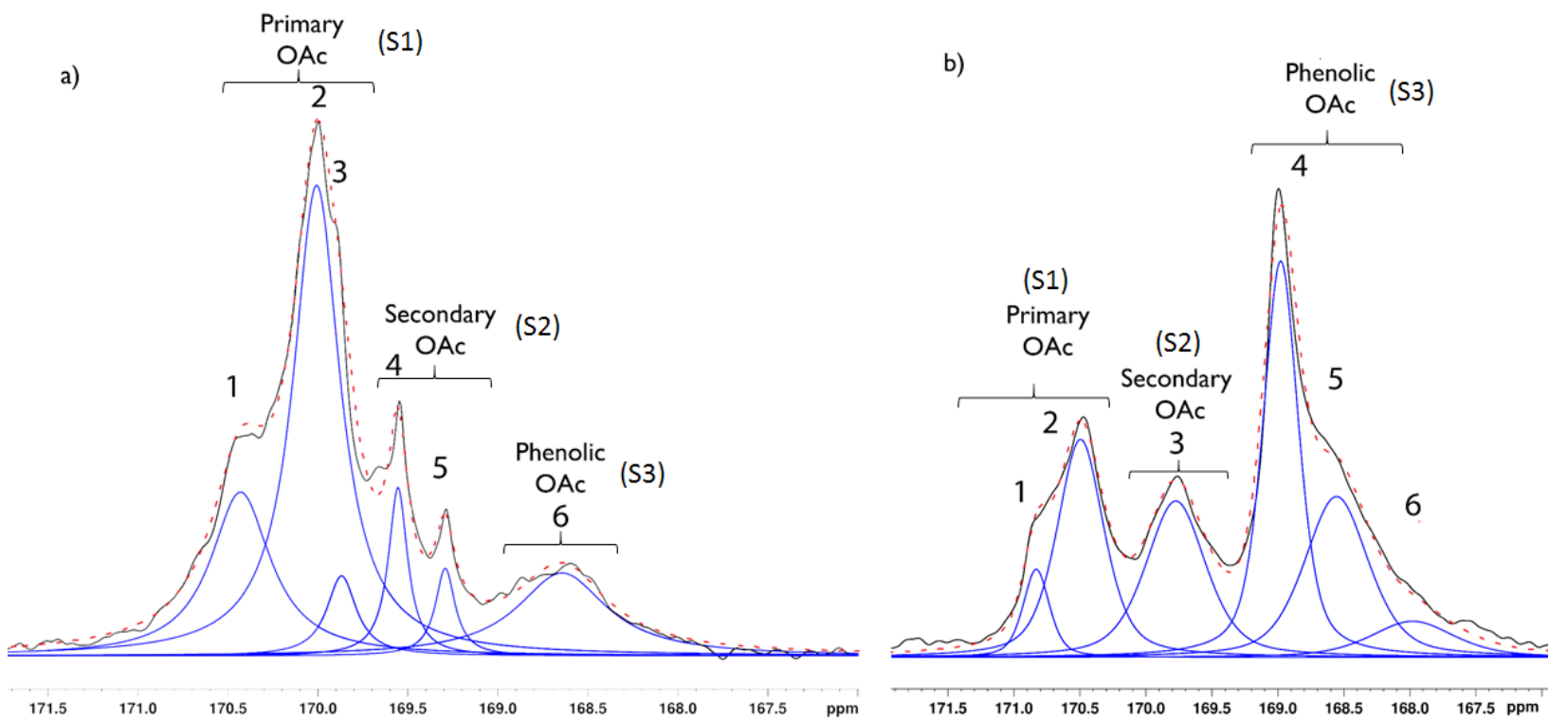

Fig. 4 Deconvoluted ${ }^{13} \mathrm{C}-\mathrm{NMR}$ spectra of acetylated (a) milox and (b) Indulin AT lignin in the acetylated hydroxyl group region. The continuous black line is the experimental signal, the blue peak curves are the deconvoluted/fitted peaks, and the dashed red line is the sum of the fit. 
Table 4 Details of the linear regressions, where $\Delta a_{\max } b$ is the slope

\begin{tabular}{|c|c|c|c|c|c|c|}
\hline & & Conc. $\left(\mathrm{mg} \cdot \mathrm{L}^{-1}\right)$ & $\Delta \mathrm{A}_{\max }$ & Data points & $\begin{array}{l}\Delta a_{\max } b \\
(\mathrm{~L} \cdot \mathrm{g}-1 \cdot \mathrm{cm}-1)\end{array}$ & $\mathrm{R}^{2}$ \\
\hline \multicolumn{7}{|l|}{ Indulin AT } \\
\hline \multirow[t]{3}{*}{$\mathrm{pH} 12-\mathrm{pH} 6$} & $\lambda(\mathrm{nm})$ & & & & & \\
\hline & 300 & $0.9-46.0$ & $0.010-0.297$ & 10 & 6.9866 & 0.9844 \\
\hline & 360 & $0.9-46.0$ & $0.010-0.361$ & 10 & 7.8966 & 0.9971 \\
\hline \multirow{3}{*}{$\begin{array}{l}\mathrm{pH} \geq 14(0.2 \mathrm{~N} \\
\mathrm{NaOH})-\mathrm{pH} 6\end{array}$} & $\lambda(\mathrm{nm})$ & & & & & \\
\hline & 300 & $0.9-46.0$ & $0.014-0.328$ & 10 & 7.9543 & 0.9729 \\
\hline & 360 & $0.9-46.0$ & $0.013-0.387$ & 10 & 8.5589 & 0.9955 \\
\hline \multicolumn{7}{|l|}{ Milox } \\
\hline \multirow[t]{3}{*}{$\mathrm{pH} 12-\mathrm{pH} 6$} & $\lambda(\mathrm{nm})$ & & & & & \\
\hline & 300 & $1.8-45.6$ & $0.007-0.059$ & 9 & 1.1253 & 0.7797 \\
\hline & 360 & $1.8-45.6$ & $0.004-0.035$ & 9 & 0.7634 & 0.7573 \\
\hline \multirow{3}{*}{$\begin{array}{l}\mathrm{pH} \geq 14(0.2 \mathrm{~N} \\
\mathrm{NaOH})-\mathrm{pH} 6\end{array}$} & $\lambda(\mathrm{nm})$ & & & & & \\
\hline & 300 & $1.8-45.6$ & $0.007-0.114$ & 9 & 1.9516 & 0.7964 \\
\hline & 360 & $1.8-45.6$ & $0.003-0.055$ & 9 & 1.0250 & 0.7987 \\
\hline
\end{tabular}

\section{$3.2 \Delta \varepsilon$-IDUS results}

Figure 5 shows the $\Delta A$-spectrum for Indulin AT and milox for the samples with $0.2 \mathrm{M} \mathrm{NaOH}$ at a concentration of $0.05 \mathrm{~g} / \mathrm{L}$. The $\Delta A$-spectra for the Indulin AT lignin had a generally higher difference absorbance throughout the whole wavelength range between $230-400 \mathrm{~nm}$ and naturally larger $\Delta A$ maxima. The maxima have slightly different locations for each lignin. This observation may arise from the expected structural difference between different types of lignins. Throughout the whole concentration range, the increase of difference absorbance is practically linear, which enables reliable calculations of the maximum difference mass absorptivities $\left(\Delta a_{\max }\right)$ and therefore the concentration of phenolic hydroxyl groups (Table 4).

Lin [24] recommends that the concentration of the sample should give an absorbance between 0.2 and 0.8 while Zakis [25] suggests a final concentration between 0.04 and $0.06 \mathrm{~g} / \mathrm{L}$, and the procedure by Gärtner [14] utilizes a concentration of about $0.08 \mathrm{~g} / \mathrm{L}$. Ultimately, the lignin and solvent in question will determine the appropriate concentration, which should ideally be large enough for a clear measurement, as well as small enough that it remains within the area where the BeerLambert Law applies. The procedure by Lin [24] utilizes only the information from the $\Delta A$-spectrum with a $\mathrm{pH} 12$ buffer, while Zakis [25] and Gärtner et al. [14] also utilize the one with $0.2 \mathrm{M} \mathrm{NaOH}$. The disadvantage of the former [24] is that it neglects the C5-substituted structures which are not be ionized at pH 12. The procedure by Gärtner et al. [14] adds a term to the equations from Zakis [25] to correct for an apparent misprint and conceptually reinterprets the conjugated model structures to add those with $\alpha-\beta$ double bond.

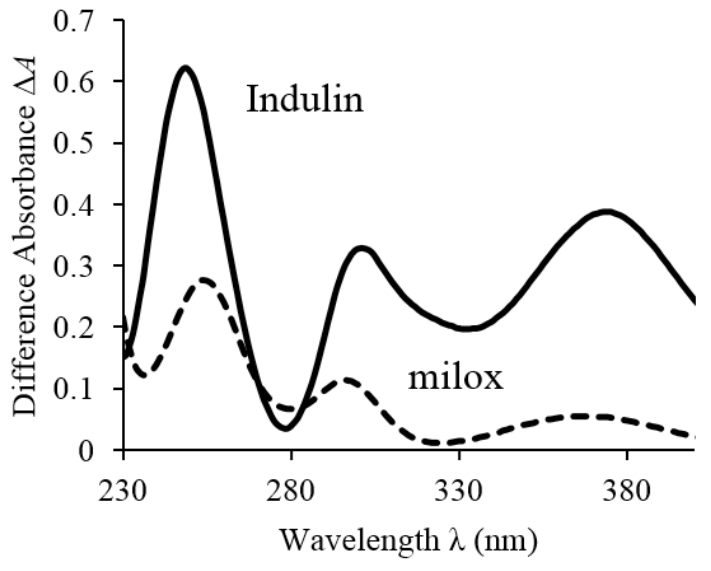

Fig. $5 \Delta A$-spectra with $0.2 \mathrm{M} \mathrm{NaOH}$ at $0.05 \mathrm{~g} / \mathrm{L}$.

The results of the slope analysis with two different calculation procedures for Indulin AT and milox lignins are shown in Table 5 and Table 6 , respectively. The calculated values of the phenolic hydroxyl group content for Indulin AT using the calculation procedure of [24] gave a significantly lower amount $(1.95 \mathrm{mmol} / \mathrm{g})$ than the previously reported values (below the $99 \%$ C.I.). The total $\mathrm{OH}_{\mathrm{ph}}$ calculated by the procedures by [25] and [14] $(2.88 \mathrm{mmol} / \mathrm{g})$ was similar to previously reported values by UV method (2.49 [33] and 2.64 [14] mmol/g) and fell within the $99 \%$ C.I. The values for the milox lignin were significantly smaller than for Indulin AT; they differed by a factor of five. However, the milox lignin appeared to have similar amount of C5-substituted and uncondensed units, whereas Indulin AT had mostly uncondensed $\mathrm{OH}_{\mathrm{ph}}$ units. 
Table 5 Phenolic hydroxyl group content in Indulin AT lignin $\left(\mathrm{mmol}_{\mathrm{OH}} / \mathrm{g}_{\mathrm{Lignin}}\right)$ determined by the $\Delta \varepsilon$-IDUS method.

\begin{tabular}{llllll}
\hline $\begin{array}{l}\text { Calc. } \\
\text { Proc. }\end{array}$ & $\begin{array}{l}\text { Cond. } \\
\text { C5-subs. }\end{array}$ & Uncond. & Conj. & Unconj. & $\begin{array}{l}\text { Total } \\
\mathrm{OH}_{\mathrm{ph}}\end{array}$ \\
\hline$[24]$ & - & 1.95 & 0.25 & 1.70 & 1.95 \\
{$[14][25]$} & 0.28 & 2.60 & 0.40 & 2.48 & 2.88 \\
\hline
\end{tabular}

The Indulin AT results based on the calculation procedure by [24] agree accurately with the reported uncondensed amount of OHph (1.92 - $2.55 \mathrm{mmol} / \mathrm{g})$ from Table 1. However, the results underestimate the total amount of phenolic hydroxyl groups, perhaps due to the fact that [24] utilized only the $\Delta A$-spectra obtained from the solutions with $\mathrm{pH} 12$ buffer, which might not be enough to ionize all structures. In addition, the procedure utilizes different model structures than the structures from the procedures by [25] and by [14].

Table 6 Phenolic hydroxyl group content in milox lignin $\left(\mathrm{mmol}_{\mathrm{OH} / \mathrm{gLignin}}\right)$ determined by the $\Delta \varepsilon$-IDUS method.

\begin{tabular}{llllll}
\hline $\begin{array}{l}\text { Calc. } \\
\text { Proc. }\end{array}$ & $\begin{array}{l}\text { Cond. } \\
\text { C5-subs. }\end{array}$ & Uncond. & Conj. & Unconj. & $\begin{array}{l}\text { Total } \\
\mathrm{OH}_{\mathrm{ph}}\end{array}$ \\
\hline$[24]$ & - & 0.30 & 0.025 & 0.275 & 0.30 \\
{$[14][25]$} & 0.235 & 0.365 & 0.05 & 0.55 & 0.60 \\
\hline
\end{tabular}

Even with the limited information available in the literature about on the condensed and uncondensed amounts of $\mathrm{OH}_{\mathrm{ph}}$ in Indulin AT, the available data (Table 1) compared to the results shows that the $\Delta \varepsilon$-IDUS method determines the amount of uncondensed $\mathrm{OH}_{\mathrm{ph}}$ reliably and within range of the reported values. However, it does seem to have a small negative deviation in the amount of condensed $\mathrm{OH}_{\mathrm{ph}}$, This is possibly due to highly cross-linked condensed units having ionization resistance because of steric hindrance, as the $\mathrm{OH}_{\mathrm{ph}}$ from uncondensed (terminal) units would be more easily accessible. Additionally, it has been previously reported [40] that the $\Delta \varepsilon$-method yields slightly smaller values for the total amount of $\mathrm{OH}_{\mathrm{ph}}$ in Indulin AT due to a second phenolic hydroxyl group in structures of the type biphenyl or catechol, which are not detected by the method. The results of this study support this, as the amount of phenolic hydroxyl groups in Indulin AT calculated by the $\Delta \varepsilon$-IDUS method yielded clearly smaller total $\mathrm{OH}_{\mathrm{ph}}(2.88 \mathrm{mmol} / \mathrm{g})$ than ${ }^{13} \mathrm{C}-\mathrm{NMR}(3.84 \mathrm{mmol} / \mathrm{g})$. This is further confirmed by previously reported values, where the phenolic hydroxyls determined were $2.49 \mathrm{mmol} / \mathrm{g}$ by UV and $3.43 \mathrm{mmol} / \mathrm{g}$ by ${ }^{1} \mathrm{H}-\mathrm{NMR}$ [33]. It is to be noted that the difference in both cases is of about $1 \mathrm{mmol} / \mathrm{g}$ between UV and NMR; an underestimation of about $25 \%$ and $27 \%$ respectively.

In the analysis of milox lignin, there was no considerable difference between the total $\mathrm{OH}_{\mathrm{ph}}$ values determined with $\Delta \varepsilon$-IDUS $(0.60 \mathrm{mmol} / \mathrm{g})$ and ${ }^{13} \mathrm{CNMR}(0.56 \mathrm{mmol} / \mathrm{g})$. This suggests that the analyzed milox lignin might have had little or practically no double phenolic hydroxyl structures or highly cross-linked condensed structures. Additionally, the difference in values between ${ }^{13} \mathrm{CNMR}$ and $\Delta \varepsilon$-IDUS for milox lignin $\mathrm{OH}_{\mathrm{ph}}$ (ca.6.7\%) could be attributed to experimental variability.

\section{Conclusions}

The $\Delta \varepsilon$-method was modified to include a slope analysis to reduce the experimental variation in calculation of the mass extinction coefficient $\Delta a_{\max }$, and the resulting method was named $\Delta \varepsilon$-IDUS. The $\Delta \varepsilon$-IDUS method allows the determination of phenolic hydroxyl groups in lignin. The method was utilized to determine the phenolic hydroxyl content of two technical lignins: pine kraft Indulin AT and birch organosolv milox lignin. Additionally, ${ }^{13} \mathrm{C}-\mathrm{NMR}$ determination of the lignins was carried out in order to compare the results with the values reported in literature and to assess the reliability of the $\Delta \varepsilon$-IDUS method.

In general, the $\Delta \varepsilon$-IDUS method has proven to be a reliable and useful one, capable of giving a prompt glance at the phenolic hydroxyl group content of lignin. This has been confirmed by the agreement of the results with the values reported in literature, and further supported by the agreement between $\Delta \varepsilon$-IDUS and ${ }^{13} \mathrm{C}$-NMR analysis of a previously uncharacterized milox lignin.

The $\Delta \varepsilon$-IDUS method allows for comparison between lignin samples through their relative reactivity as expressed by their phenolic hydroxyl content. The preferred method for deeper analysis will remain NMR due to its capabilities of elucidating in great detail the amount of different forms of hydroxyl groups in lignin. Since the presence of a second phenolic hydroxyl (e.g. biphenyl, catechol) in some units is neglected by the $\Delta \varepsilon$-IDUS method, it is wise to regard it as a semi-quantitative screening method. For detailed description of the hydroxyl groups, NMR has remained state-of-the-art.

Ideally, methods to characterize lignin would not need laborious pre-treatments or derivatization. This might not prove to be a trivial undertaking. Lignin is so complex and heterogeneous, with different properties given by its origin and isolation method that analysis methods have to be developed, adjusted, and fine-tuned for every group of lignins with similar characteristics. Due to the relatively simple pretreatment and derivation procedures of $\Delta \varepsilon$-IDUS in comparison to NMR, the $\Delta \varepsilon$-IDUS method becomes one of the most cost- and time effective ways to screen and compare lignin samples based on one of their most important properties, the phenolic hydroxyl group content.

\section{Acknowledgement}

The financial support of the Academy of Finland (grant numbers 289649 and 294027) is gratefully acknowledged. 


\section{References}

[1] Lewis, N. G., Yamamoto, E. "Lignin: Occurrence, Biogenesis and Biodegradation." Annual Review of Plant Physiology and Plant Molecular Biology. 41, pp. 455-496. 1990.

https://doi.org/10.1146/annurev.pp.41.060190.002323

[2] Thielemans, W. J., Can, E., Morye, S. S., Wool, R. P. "Novel applications of lignin in composite materials." Journal of Applied Polymer Science. 83(2), pp. 323-331. 2002. https://doi.org/10.1002/app.2247

[3] Alén, R. "Papermaking science and technology. Book 20, Biorefining of forest resources." Paperi ja Puu, Helsinki. 2011.

[4] Li, J., Gellerstedt, G., Toven, K. "Steam explosion lignins; their extraction, structure and potential as feedstock for biodiesel and chemicals." Bioresource Technology. 100(9), pp. 2556-2561. 2009.

https://doi.org/10.1016/j.biortech.2008.12.004

[5] Lai, Y.-Z., Guo, X.-P. "Variation of the phenolic hydroxyl group content in wood lignins." Wood Sci Technol. 25(6), pp 467-472. 1991. https://doi.org/10.1007/BF00225239

[6] Podschun, J., Saake, B., Lehnen, R. "Reactivity enhancement of organosolv lignin by phenolation for improved bio-based thermosets." European Polymer Journal. 67, pp. 1-11. 2015. https://doi.org/10.1016/j.europolymj.2015.03.029

[7] Yu, P., He, H., Jiang, C., Wang, D., Jia, Y., Zhou, L., Jia, D. M. "Reinforcing styrene butadiene rubber with lignin-novolac epoxy resin networks." Express Polymer Letters. 9(1), pp. 36-48. 2015.

https://doi.org/10.3144/expresspolymlett.2015.5

[8] Bozsódi, B., Romhányi, V., Pataki, P., Kun, D., Renner, K., Pukánszky, B. "Modification of interactions in polypropylene/lignosulfonate blends." Material \& Design. 103, pp. 32-39. 2016.

https://doi.org/10.1016/j.matdes.2016.04.061

[9] Hilburg, S. L., Elder, A. N., Chung, H., Ferebee, R. L., Bockstaller, M. R., Washburn, N. R. "A universal route towards thermoplastic lignin composites with improved mechanical properties." Polymer. 55(4), pp. 995-1003. 2014. https://doi.org/10.1016/j.polymer.2013.12.070

[10] Bernardini, J., Cinelli, P., Anguillesi, I., Coltelli, M. B., Lazzeri, A. "Flexible polyurethane foams green production employing lignin or oxypropylated lignin." European Polymer Journal. 64, pp. 147-156. 2015. https://doi.org/10.1016/j.eurpolymj.2014.11.039

[11] Estellé, P., Halelfadl, S., Maré, T. "Lignin as dispersant for water-based carbon nanotubes nanofluids: Impact on viscosity and thermal conductivity." International Communications in Heat and Mass Transfer. 57, pp. 8-12. 2014. https://doi.org/10.1016/j.icheatmasstransfer.2014.07.012

[12] Lundquist, K., Parkas, J. "Different Types of Phenolic Units in Lignins." BioResources. 6(2), pp. 920-926. 2011. URL: ncsu.edu/bioresources/ BioRes_06/BioRes_06_2_0920_Lundquist_Parkas_Distrib_Phenolic Units_in_Lignins_1427.pdf

[13] Granata, A., Argyropoulos, D. S. "2-Chloro-4,4,5,5-tetramethyl-1,3,2dioxaphospholane, a Reagent for the Accurate Determination of the Uncondensed and Condensed Phenolic Moieties in Lignins." Journal of Agricultural and Food Chemistry. 43(6), pp. 1538-1544. 1995. https://doi.org/10.1021/jf00054a023

[14] Gärtner, A., Gellerstedt, G., Tamminen, T. "Determination of phenolic hydroxyl groups in residual lignin using a modified UV-method." Nordic Pulp and Paper Research Journal. 14(02), pp. 163-170. https://doi.org/10.3183/NPPRJ-1999-14-02-p163-170

[15] Bostanabad, A. S., Sadeghifar, H., Khalilzadeh, M. A. "Characterization of lignin isolated from Iranian Fagus orientalis wood." Iranian Journal of Organic Chemistry. 1(1), pp. 29-32. URL: iranjoc.com/upfiles/Journals/vol1no1/j1a23.pdf
[16] Himmel, M. E., Tatsumoto, K., Oh, K. K., Grohmann, K., Johnson, D. K., Li Chum, H. "Molecular Weight Distribution of Aspen Lignins Estimated by Universal Calibration." In: Glasser, S., Sarkanen, S. (eds.) Lignin: Properties and Materials. ACS Symposium Series, Vol. 397, Chapter 6, pp. 82-99. 1989.

https://doi.org/10.1021/bk-1989-0397.ch006

[17] Tolbert, A., Akinosho, H., Khunsupat, R., Naskar, A. K., Ragauskas, A. J. "Characterization and analysis of the molecular weight of lignin for biorefining studies." Biofuels Bioproducts \& Biorefining. 8(6), pp. 836856. 2014. https://doi.org/10.1002/bbb.1500

[18] Ház, A., Jablonský, M., Orságová, A., Šurina, I. "Characterization of lignins by PY-GC/MS." In: 4nd International Conference Renewable Energy Sources 2013. Tatranské Matliare, High Tatras, Slovak Republic, May 21-23, 2013. URL: researchgate.net/publication/236986670_Characterization_of_lignins_by_PyGCMS

[19] Jakab, E., Faix, O., Till, F., Székely, T. "Thermogravimetry/mass spectrometry study of six lignins within scope of an international round robin test." Journal of Analytical and Applied Pyrolysis. 35(2), pp. 167-179. https://doi.org/10.1016/0165-2370(95)00907-7

[20] Fiţigău, I. F., Peter, F., Boeriu, C. G. "Structural Analysis of Lignins from Different Sources." International Journal of Chemical, Molecular, Nuclear, Materials and Metallurgical Engineering. 7(4), pp. 167-172. URL: waset.org/publications/4184/structural-analysis-of-lignins-fromdifferent-sources

[21] Ton That, M.-T., Ngo, T.-D., Lebarbé, T., Bélanger, C., Hu, W., Ahvazi, B., Al-Hawari, J., Monteil-Rivera, F., Pilon, A., Langlois, A. "Development of Ligno-Polyol for the production of Polyurethanes." In: Polyurethanes 2010-Technical Conference, Houston, Texas, USA, October 11-13, 2010. URL: nparc.cisti-icist.nrc-cnrc.gc.ca/npsi/ ctrl?action $=$ rtdoc \&an $=17646997$

[22] Li, S., Lundquist, K. "A new method for the analysis of phenolic groups in lignins by 1H NMR spectroscopy." Nordic Pulp and Paper Research Journal. 9(3), pp. 191-195. 1994. URL: publications.lib.chalmers.se/records/fulltext/local_130956.pdf

[23] Berlin, A., Balakshin, M. "Chapter 18 - Industrial Lignins: Analysis, Properties, and Applications." In: Gupta, V. K., Kubicek, M. G. T. P., Xu, J. S. (eds.) Bioenergy Research: Advances and Applications. Elsevier, Amsterdam, pp. 315-336. 2014. https://doi.org/10.1016/B978-0-444-59561-4.00018-8

[24] Lin, S. Y., Dence, C. W. "Methods in Lignin Chemistry. Springer Series in Wood Science." Springer Verlag, Berlin, Heidelberg, 1992. https://doi.org/10.1007/978-3-642-74065-7

[25] Zakis, G. F. "Functional analysis of lignins and their derivatives." Atlanta, Ga., TAPPI Press, 1994.

[26] Sindhu, P. S. "Fundamentals of Molecular Spectroscopy." New Delhi, New Age International, 2006.

[27] Rousu, P., Rousu, P., Anttila, J. "Sustainable pulp production from agricultural waste." Resources, Conservation and Recycling. 35(1-2), pp. 85-103. 2002. https://doi.org/10.1016/S0921-3449(01)00124-0

[28] Seisto, A., Poppius-Levlin, K. "Formic acid/peroxyformic acid pulping of birch - delignification selectivity and zero-span strength." Nordic Pulp and Paper Research Journal. 12(03), pp. 155-161. 1997. https://doi.org/10.3183/NPPRJ-1997-12-03-p155-161

[29] Choi, J. W., Faix, O. "NMR study on residual lignins isolated from chemical pulps of beech wood by enzymatic hydrolysis." Journal of Industrial and Engineering Chemistry. 17(1), pp. 25-28. 2011. https://doi.org/10.1016/j.jiec.2010.10.004 
[30] Cateto, C. A., Barreiro, M. F., Rodrigues, A. E., Brochier-Salon, M. C., Thielemans, W., Belgacem, M. N. "Lignins as macromonomers for polyurethane synthesis: A comparative study on hydroxyl group determination." Journal of Applied Polymer Science. 109(5), pp. 3008-3017. 2008. https://doi.org/10.1002/app.28393

[31] Faix, O., Argyropoulos, D. S., Robert, D., Neirinck, V. "Determination of Hydroxyl Groups in Lignins Evaluation of ${ }^{1} \mathrm{H}-,{ }^{13} \mathrm{C}-,{ }^{31} \mathrm{P}-\mathrm{NMR}$, FTIR and Wet Chemical Methods." Holzforschung - International Journal of the Biology, Chemistry, Physics and Technology of Wood. 48(5), pp. 387394. 1994. https://doi.org/10.1515/hfsg.1994.48.5.387

[32] Milne, T. A., Chum, H. L., Agblevor, F., Johnson, D. K. "Standardized analytical methods." Biomass Bioenergy. 2(1-6), pp. 341-366. 1992. https://doi.org/10.1016/0961-9534(92)90109-4

[33] Tiainen, E., Drakenberg, T., Tamminen, T., Kataja, K., Hase, A. "Determination of Phenolic Hydroxyl Groups in Lignin by Combined Use of $1 \mathrm{H}$ NMR and UV Spectroscopy." Holzforschung - International Journal of the Biology, Chemistry, Physics and Technology of Wood. 53(5), pp. 529-533. 1999. https://doi.org/10.1515/HF.1999.087

[34] Månsson, P. "Quantitative Determination of Phenolic and Total Hydroxyl Groups in Lignins." Holzforschung - International Journal of the Biology, Chemistry, Physics and Technology of Wood. 37(3), pp. 143-146. 1983. https://doi.org/10.1515/hfsg.1983.37.3.143
[35] Ingle, J. D., Crouch, S. R. "Spectrochemical Analysis." New Jersey, Prentice Hall. 1988.

[36] Wen, J.L., Sun, S.-L., Xue, B.-L., Sun, R.-C. "Recent Advances in Characterization of Lignin Polymer by Solution-State Nuclear Magnetic Resonance (NMR) Methodology." Materials. 6(1), pp. 359-391. 2013. https://doi.org/10.3390/ma6010359

[37] Cateto, C. A., Barreiro, M. F., Rodrigues, A. E. "Lignin characterization by acetylation procedures." In: 9th International Chemical Engineering Conference - CHEMPOR. Coimbra, Portugal, 2005, pp. 60-61. URL: hdl.handle.net/10198/5053

[38] Thring, R. W., Chornet, E., Bouchard, J., Vidal, P. F., Overend, R. P. "Evidence for the heterogeneity of glycol lignin." Industrial \& Engineering Chemistry Research. 30(1), pp. 232-240. 1991. https://doi.org/10.1021/ie00049a036

[39] Argyropoulos, D. S., Sun, Y., Mazur, M. "Milox pulping: Lignin characterization by ${ }^{31} \mathrm{P}$ NMR spectroscopy and oxidative degradation." Nordic Pulp and Paper Research Journal. 10(01), pp. 68-73. 1995. https://doi.org/10.3183/NPPRJ-1995-10-01-p068-073

[40] Schmidt, J. A. "Electronic Spectroscopy of Lignins." In: Heitner, C., Dimmel, D., Schmidt, J. (eds.) Lignin and Lignans: Advances in Chemistry. CRC Press, pp. 49-102. 2010. https://doi.org/10.1201/EBK1574444865-c3 